\title{
Be Mindful, Less Stress: Studi Tentang Mindful Parenting Dan Stres Pengasuhan Pada Ibu Dari Anak Usia Middle Childhood Di Jakarta
}

\author{
Izmiyah Afaf Abdul Gani', Dewi Kumalasari ${ }^{2}$ \\ ${ }^{1}$ Fakultas Psikologi Universitas Yarsi, Jakarta, Indonesia \\ email: Izmiyah.afaf@gmail.com
}

\begin{abstract}
Artikel INFO
Diterima:12 Sep 2019

Direvisi :01 Nov 2019

Disetujui:02 Des 2019

DOI:

http://dx.doi.org/10.24014/ jp.v14i2.7744
\end{abstract}

\section{Abstrak}

\begin{abstract}
Mengasuh anak usia sekolah dasar merupakan salah satu tugas ibu yang penuh tantangan sehingga jika ibu tidak mampu mengatasi tantangan ini, maka ibu rentan mengalami stres pengasuhan. Penelitian ini bertujuan untuk menguji peran mindful parenting terhadap stres pengasuhan pada ibu yang memiliki anak usia sekolah dasar. Penelitian menggunakan pendekatan penelitian kuantitatif Partisipan penelitian berjumlah 110 ibu berusia 28-46 tahun. Teknik pengambilan data yang digunakan adalah sampling insidental. Alat ukur Parental Stress Scale (PSS) digunakan untuk mengukur stres pengasuhan dengan reliabilitas 0,906, kemudian alat ukur Mindfulness in Parenting Scale (MIPQ) digunakan untuk mengukur mindful parenting dengan reliabilitas 0,818 . Hasil uji hipotesa secara regresi sederhana menunjukkan bahwa terdapat peran negatif secara signifikan mindful parenting terhadap stres pengasuhan. Ketika ibu mengaplikasikan mindful parenting maka semakin rendah stres pengasuhan yang dialaminya. Hasil penelitian ini dapat dijadikan rujukan untuk mengatasi stres pengasuhan yang dialami oleh ibu yang memiliki anak usia sekolah dasar melalui edukasi masyarakat mengenai peran mindful parenting terhadap stres pengasuhan.
\end{abstract}

Kata Kunci: Ibu, Anak Usia Sekolah Dasar, Stres Pengasuhan, Mindful Parenting

\section{Be Mindful, Less Stress: Study About Mindful Parenting And Parenting Stress Among Mother Of Middle Childhood Aged Children In Jakarta}

\begin{abstract}
Parenting for school-age children is one of the challenging tasks of the mother so that if the mother is unable to overcome this challenge, the mother is vulnerable to parenting stress. This is study aims to determine the role of mindful parenting towards parenting stress in mother of school-age children. This study uses a quantitative research approach with associative design. The total subjects of this research are 110 mothers and their age range is between 28-46 years old. Accidental sampling was used to collected the data. The Parental Stress Scale (PSS) was used to measured parental stress, has a reliability of 0.906 , then the Mindfulness in Parenting Scale (MIPQ) was used to measured mindful parenting, has a reliability of 0.818 . The research hypothesis was tested using Simple Linear Regression analysis. The result of the research hypothesis showed that there's a negative role of mindful parenting towards parenting stress in mother of school-age children. When mothers apply mindful parenting, the lower the stress of caregiving they experience. Therefore, the results of this study can be used as a reference to deal with parenting stress through public education about the role of mindful parenting towards parenting stress.
\end{abstract}

Keywords: Mother, School-aged children, Parenting stress, Mindful Parenting

\section{Pendahuluan}

Peran sebagai orangtua dapat menjadi sesuatu yang membahagiakan sekaligus penuh dengan tantangan (Sanders \& Turner, dalam Sanders \& Morawska, 2018). Tantangan pengasuhan yang dihadapi oleh orangtua terutama dialami oleh ibu akan bertambah seiring dengan bertambahnya usia anak, salah satunya yaitu ketika anak memasuki tahapan perkembangan middle childhood atau yang biasa disebut usia sekolah dasar.

Tahap perkembangan usia sekolah dasar (middle childhood) merupakan salah satu tahap perkembangan krusial yang terkadang tidak diperhatikan dalam tahap perkembangan manusia (Del Giudice, 2014). Padahal, tahap 
perkembangan ini juga merupakan salah satu fase perkembangan yang tak kalah penting dalam rentang kehidupan manusia (Del Giudice, 2014). Menurut Grusec, Chaparo, Johnston, dan Sherman (dalam Santrock, 2013), orangtua menghabiskan waktu yang lebih sedikit seiring dengan anak-anak mereka yang mulai memasuki tahapan usia sekolah dasar. Hal ini salah satunya disebabkan karena interaksi dengan teman sebaya yang menjadi lebih sering (Rubin, Pukowski, \& Parker, dalam Santrock, 2013). Namun walau demikian, peran orangtua di tahap perkembangan anak ini juga semakin penting (Santrock, 2013).

Ketika anak berada di tahap usia sekolah dasar, orangtua memiliki beban tambahan dan tanggung jawab tambahan, karena jejaring sosial anak berkembang secara signifikan selama masa ini (Collins, Madsen, \& SusmanStillman, dalam Bornstein, 2002). Di masa ini, interaksi anak tidak terbatas hanya pada anggota keluarga atau orang-orang yang mengunjungi rumahnya lagi. Seiring dengan interaksi anak yang semakin luas dengan lingkungannya, ibu perlu melakukan usaha lebih dalam melakukan pengawasan terhadap anak mereka.

Ketika anak berada ditahap perkembangan usia sekolah, fungsi kognitif mereka mulai berkembang lebih baik dari masa sebelumnya (Collins, Madsen, \& Susman-Stillman, dalam Bornstein, 2002). Sejalan dengan fungsi kognitif yang bertambah, orangtua juga mulai mengembangkan ekspektasi mereka terhadap anak (Goodnow, 1988; Collins, Madsen, \& Susman-Stillman, dalam Bornstein, 2002). Ekspektasi yang dimiliki oleh orangtua, khususnya ibu juga terkait dengan anak mereka yang mulai memasuki dunia sekolah. Di masa ini, salah satu ekspektasi yang dimiliki oleh orangtua yaitu, anak dapat lebih mandiri dalam hal tugas sekolah dan rumah, serta saat berinteraksi dengan teman sebaya (Hartup, dalam Bornstein 2002). Selain itu, ibu juga akan memiliki ekspektasi yang lebih tinggi pada anak agar memiliki pencapaian sekolah yang baik. Penelitian yang dilakukan oleh Lee dan Stevenson (dalam Bornstein, 2002) menyatakan bahwa orangtua di Asia memiliki ekspektasi yang lebih tinggi mengenai pentingnya pencapaian di sekolah dibandingkan dengan orangtua di Amerika. Ekspektasi yang dimiliki oleh ibu dapat menjadi tantangan bagi anak maupun ibu sendiri. Dengan adanya ekspektasi tersebut, anak harus berusaha agar dapat memenuhi pencapaian sekolah yang diinginkan oleh ibunya. Ketika anak tidak berhasil mencapai hal tersebut, maka ibu perlu melakukan sesuatu agar anak dapat memiliki pencapaian sekolah yang baik.

Salah satu tantangan pengasuhan ibu yang memiliki anak usia sekolah dasar ini dapat bersumber dari tuntutan keterampilan yang harus dikuasai oleh anak maupun terkait dengan kehidupan sekolah anak. Sebagai contoh, saat ini di Indonesia diterapkan sebuah kurikulum pelajaran yang dinamakan dengan kurikulum 2013. Di kurikulum 2013 ini, anak kelas 1 Sekolah Dasar mendapat tuntutan baru, yakni untuk menguasai calistung (membaca, menulis, dan berhitung). Hal ini tentu saja menjadi tuntutan baru bagi orangtua untuk memerhatikan pola belajar anak serta mengajari anak-anaknya yang akan memasuki sekolah dasar untuk menguasai ketiga hal tersebut (Marbun, 2015).

Contoh lainnya yaitu metode yang diterapkan oleh kurikulum 2013 ini menitikberatkan pada tugas mandiri yang biasanya memerlukan pendampingan dari orangtua, atau dengan kata lain tidak dapat dikerjakan sendiri oleh anak. Hal ini berakibat pada bertambahnya tugas maupun beban baru bagi orangtua, yakni untuk membantu anakanak mereka dalam mengerjakan pekerjaan rumah. Tugas baru yang dimiliki oleh orangtua ini sering dikeluhkan oleh para orangtua yang merasa direpotkan oleh tugas sekolah anak mereka (Hasibuan, 2015). Jika ibu tidak dapat menghadapi tantangan yang dimilikinya serta tidak dapat menyeimbangkan tuntutan seperti contoh diatas dengan sumber daya yang mereka miliki, maka hal ini dapat menyebabkan suatu reaksi tekanan yang disebut dengan stres (McGrath, dalam Baqutayan, 2015).

Stres merupakan sesuatu yang tidak terelakkan dan merupakan pengalaman normal yang dirasakan oleh individu ketika individu tersebut tidak yakin bahwa ia dapat 
memenuhi tuntutan lingkungannya (Patnaik, dalam Cronin, Becher, Christians, Maher, \& Dibb, 2015). Stres dapat dialami oleh siapa saja, salah satunya adalah orangtua. Stres yang dialami oleh orangtua dalam kaitannya dengan tuntutan pengasuhan anak-anak mereka ini disebut dengan stres pengasuhan (Abidin, dalam Pinquart, 2017).

Stres pengasuhan didefinisikan sebagai pengalaman emosi negatif yang dirasakan oleh orangtua sebagai respon terhadap tuntutan untuk menjadi orangtua (Widarsson, Engström, Rosenblad, Kerstis, Edlund, \& Lundberg, 2012). Definisi perasaan negatif yang ada dalam stres pengasuhan diatribusikan secara langsung pada tuntutan individu sebagai orangtua (Deater-Deckard, dalam Widarsson dkk, 2012). Jika stres pengasuhan tidak segera diatasi, maka hal itu akan berdampak buruk bagi orangtua maupun bagi anak.

Menurut penelitian, stres pengasuhan ditemukan memiliki pengaruh besar terhadap keterampilan pengasuhan, seperti: saat stres, orangtua menjadi lebih banyak memberikan penolakan, lebih mengontrol, reaktif, serta menjadi kurang hangat terhadap anak-anak mereka (Belsky, 1984; Webster-Stratton, dalam Bögels, Lehtonen, \& Restifo, 2010). Selain berdampak pada orangtua, stres pengasuhan juga diasosiasikan dengan dampak negatif pada kondisi psikologis anak-anak (DeaterDeckard, 2004; Neece, 2014; Robinson \& Neece, dalam Gouveia, Carona, Canavarro, \& Moreira, 2016) seperti munculnya simtomsimtom kecemasan, depresi, hingga keluhan somatik (Deater-Deckard, 2004), serta dapat menyebabkan hubungan yang bermasalah antara anak dan orangtua (Belsky, 1984; Bögels, Lehtonen, \& Restifo, 2010; WebsterStratton, dalam Gouveia, Carona, Canavarro, \& Moreira, 2016) seperti penerapan hukuman berlebihan dan lebih sedikit memberikan penghargaan pada (Stoneman, Brody, \& Burke, dalam Webster-Stratton, 1990).

Beberapa penelitian sebelumnya menyebutkan bahwa ibu mengalami stres pengasuhan yang lebih banyak dibandingkan ayah (Ostberg \& Hagekull, 2000; Jackson, Ternedest, Magnuson, \& Schollin, dalam Widarsson dkk, 2012). Skreden, Skari, Malt,
Pripp, Bjork, Faugli, dan Emblem (dalam Daulay, 2016) menemukan bahwa ibu memiliki skor stres pengasuhan lebih tinggi, lebih mudah stres, dan kurang sejahtera dibandingkan ayah. Terdapat beberapa faktor yang dapat menyebabkan stres pada ibu rumah tangga, seperti: merawat orangtua, merawat anak, dan merawat anak dengan kebutuhan khusus (Waisbren, Rones, Read, Marsden, \& Levy, dalam Feizi, Najmi, Salesi, Chorami, \& Hoveidafar, 2014).

Berdasarkan penelitian Barnett dan Baruch (dalam Berry \& Jones, 1995) disebutkan bahwa peran sebagai orangtua dapat menjadi sumber stres yang paling penting dalam kehidupan wanita karena adanya tanggung jawab besar yang menyertainya. Meningkatnya stres pengasuhan pada ibu diasosiasikan dengan tingkat pendidikan yang rendah, banyaknya jumlah anak, kurangnya dukungan sosial, dan usia saat menjadi ibu (Ostberg \& Hagekull, dalam Skreden, Skari, Malt, Pripp, Bjork, Faugli, \& Emblem, 2012). Untuk meminimalisir terjadinya stres pengasuhan pada ibu, dibutuhkan suatu kemampuan pengasuhan yang adaptif dan positif seperti komunikasi yang lebih baik antara orangtua dan anak, maupun penerapan disiplin yang lebih konsisten (Duncan, Coatsworth, \& Greenberg, dalam Gouveia, Carona, Canavarro, \& Moreira, 2016) seperti yang terdapat pada mindful parenting.

Beberapa penelitian sebelumnya mendukung anggapan bahwa mindfulparenting memiliki peran terhadap berkurangnya penerapan disiplin yang disfungsional (de Bruin, Zijlstra, Geurtzen, van Zundert, van de WeijerBergsma, Hartman, \& Bögels, dalam Medeiros, Gouveia, Canavarro, \& Moreira, 2016) serta stres pengasuhan yang lebih rendah (Beer, Ward, \& Moar, 2013; Bögels, Hellemans, van Deursen, Römer, \& van Der Meulen, 2014; Bögels \& Restifo, 2014; Gouveia, Canavarro, \& Moreira, dalam Medeiros, Gouveia, Canavarro, \& Moreira, 2016). Menurut Kabat-Zinn dan Kabat-Zinn (dalam McCaffrey, Reitman, \& Black, 2016) mindful parenting didefinisikan sebagai memberi perhatian kepada anak dan cara pengasuhan yang diberikan secara khusus, dengan cara meningkatkan intensitas hubungan orangtua dan anak, fokus pada 
keadaan saat ini, dan tanpa memberikan penilaian. Mindful parenting diasumsikan dapat menghasilkan pengurangan tingkat reaktivitas serta meningkatkan kesabaran, fleksibilitas, pengasuhan, ketanggapan, konsistensi, serta pengasuhan oleh yang sesuai dengan tujuan dan nilai yang dimiliki oleh orangtua (Duncan, Coatsworth, \& Greenberg, dalam McCaffrey, Reitman, \& Black, 2016). Orangtua yang mindful memiliki regulasi emosi yang lebih baik terhadap emosi yang muncul saat berinteraksi dengan anak-anak mereka serta dapat menangani stres pengasuhan dengan lebih baik (Bögels, Lehtonen, \& Restifo, 2010; Bögels \& Restifo, 2014; Duncan, Coatsworth \& Greenberg, dalam Medeiros, Gouveia, Canavarro, \& Moreira, 2016).

Menurut McCaffrey, Reitman, dan Black (2016) terdapat dua dimensi mindful parenting yaitu mindful discipline dan being in the moment with the child. Dimensi mindful discipline merupakan dimensi yang berfokus pada orangtua yang merefleksikan ciri parenting (pengasuhan) yang non reaktif, kesadaran akan pengasuhan, serta pengasuhan yang berfokus pada tujuan pengasuhan yang telah ditetapkan. Dimensi being in the moment with the child merupakan dimensi yang berfokus pada anak dengan memberikan perhatian akan momen yang terjadi saat ini, pemahaman empati serta penerimaan terhadap anak. Berdasarkan penelitian yang dilakukan oleh Willinger, Diendorfer-Radner, Willnauer, Jorgl dan Hagel (dalam Lestari, 2012) diketahui bahwa kombinasi empati, kedekatan, kehangatan emosi, dan afeksi di satu sisi, serta otonomi dan memperkenankan anak mandiri di sisi lain berkorelasi dengan rendahnya stres pengasuhan. Karakteristik-karakteristik ini berkaitan dengan dua dimensi mindful parenting yang dijelaskan oleh McCaffrey, Reitman, dan Black (2016).

Penelitian sebelumnya lebih banyak terfokus pada orangtua dengan anak dan orangtua dengan bayi atau anak usia pra sekolah. Penelitian ini juga akan difokuskan pada ibu yang memiliki anak usia sekolah dasar dengan rentang usia 6-11 tahun yang tinggal di Kota Jakarta. Selain itu, penelitian terkait peran mindful parenting terhadap stres pengasuhan masih sedikit dilakukan di Indonesia padahal stres pengasuhan yang dimiliki oleh ibu dapat memiliki dampak yang signifikan bagi perkembangan anak. Dalam penelitian ini peneliti ingin melihat peran mindful parenting terhadap stres pengasuhan yang pada ibu yang memiliki anak usia sekolah dasar dengan rentang usia 6-11 tahun.

\section{Metode}

Penelitian ini menggunakan metode kuantitatif. Teknik pengambilan sampel dalam penelitian ini menggunakan accidental sampling, yaitu teknik penentuan sampel berdasarkan kebetulan, yaitu siapa saja yang secara kebetulan atau insidental bertemu dengan peneliti dan memenuhi kriteria sebagai subjek penelitian, dapat digunakan sebagai sumber data (Sugiyono, 2014). Adapun karakteristik sampel penelitian ini adalah:

1. Ibu yang terlibat dalam pengasuhan anak. Hal ini diambil berdasarkan kesimpulan dari beberapa penelitian bahwa ibu mengalami stres pengasuhan yang lebih banyak dari pada ayah (Ostberg \& Hagekull, 2000; Jackson, Ternedest, Magnuson, \& Schollin, dalam Widarsson dkk, 2012; Malt, Pripp, Bjork, Faugli, \& Emblem, dalam Daulay, 2016).

2. Berdomisili di Provinsi DKI Jakarta.

3. Memiliki anak usia sekolah dasar dengan rentang usia 6-11 tahun, yang disimpulkan dari beberapa penelitian bahwa pengalaman pertama sekolah pada anak merupakan titik kritis untuk menentukan kesuksesan atau kegagalan di masa depan (Papalia \& Feldman, 2014).

Penelitian ini menggunakan instrumen penelitian berupa kuesioner yang terdiri dari dua alat ukur, yaitu Parental Stress Scale (PSS) dan Mindfulness in Parenting Questionnaire (MIPQ). PSS digunakan untuk mengukur stres pengasuhan, sedangkan MIPQ digunakan untuk mengukur mindful parenting.

Alat ukur Parental Stress Scale dikembangkan oleh Berry dan Jones (1995). Skala ini memiliki 18 aitem dan bersifat unidimensional, alat ukur ini menggunakan 
skala likert 1-5 (sangat tidak setuju - sangat setuju). Alat ukur Mindfulness in Parentimg Questionnaire (MIPQ) dirancang oleh McCaffrey, Reitman, dan Black (2016). Alat ukur MIPQ terdiri dari 28 aitem dan bersifat unidimensi. MIPQ menggunakan skala likert 1-4 (Jarang - Hampir Selalu).

Pengumpulan data menggunakan kuesioner dilakukan kepada 110 orang ibu yang memiliki anak usia sekolah dasar dan berdomisili di Jakarta. Peneliti menggunakan teknik analisis data uji normalitas dan uji regresi linear sederhana. Hasil penelitian ini diolah menggunakan software Microsoft excel 2013 dan perhitungan menggunakan SPSS for Windows 24.0.

\section{Hasil}

Hasil pengujian regresi linear sederhana sebagai berikut:

\section{Tabel 1 Hasil Regresi Mindful Parenting dan Stres Pengasuhan}

$\begin{array}{cccc}\text { R Square } & \text { F } & \text { Sig } & \begin{array}{c}\text { Persamaan } \\ \text { Regresi }\end{array} \\ \text {,397 } & 71,223 & , 000 & \begin{array}{c}\text { Y }=100,358- \\ 0,797 X\end{array}\end{array}$

Berdasarkan tabel diatas, diperoleh hasil mindful parenting berperan terhadap stres pengasuhan $(F=71,223, p<0,05)$. Selain itu diketahui nilai koefisien determinasi sebesar 0,397 . Besarnya nilai koefisien determinasi menunjukan besaran peran dalam persen, yaitu 39,7\%. Dapat disimpulkan bahwa Mindful Parenting berperan secara negatif terhadap variabel stres pengasuhan sebesar $39,7 \%$, dimana $60,3 \%$ lainnya dipengaruhi oleh faktor lain. Berdasarkan tabel diatas juga diperoleh persamaan linear $Y=100,358$ - 0,797X. Hal tersebut menunjukan bahwa setiap penambahan 1 nilai pada mindful parenting, maka nilai pada stres pengasuhan akan berkurang sebesar 0,797.

\section{Pembahasan}

Berdasarkan hasil penelitian yang dilakukan, diperoleh bahwa mindful parenting berperan terhadap stres pengasuhan pada ibu yang memiliki anak usia sekolah dasar. Peran mindful parenting yang diperoleh adalah sebesar $39,7 \%$. Ketika ibu mengaplikasikan mindful parenting maka semakin rendah stres pengasuhan yang dialaminya. Hasil ini sejalan dengan penelitian yang dilakukan oleh Beer, Ward, dan Moar (2013), Bögels, Hellemans, van Deursen, Römer, dan van Der Meulen (2014), Bögels dan Restifo (2014), Gouveia, Canavarro, dan Moreira (dalam Medeiros, Gouveia, Canavarro, \& Moreira, 2016) yang menunjukkan mindful parenting memiliki peran terhadap stres pengasuhan yang lebih rendah.

Orangtua yang mindful juga memiliki regulasi emosi yang lebih baik terhadap emosi yang muncul saat berinteraksi dengan anak-anak mereka serta dapat menangani stres pengasuhan dengan lebih baik (Bögels, Lehtonen, \& Restifo, 2010; Bögels \& Restifo, 2014; Duncan, Coatsworth \& Greenberg, dalam Medeiros, Gouveia, Canavarro, \& Moreira, 2016). Selain itu, hasil tersebut juga dapat dijelaskan oleh penelitian Dishion, Burraston, dan Li (dalam McCaffrey, Reitman, \& Black, 2016), Dumas (dalam McCaffrey, Reitman, \& Black, 2016), dan Duncan dkk. (dalam McCaffrey, Reitman, \& Black, 2016) bahwa mindful parenting memungkinkan orangtua untuk untuk memilih strategi pengasuhan yang lebih efektif. Sebagai contoh, ibu yang menerapkan mindful parenting mampu untuk mengenali tingkat stres nya yang meningkat sehingga memahami dengan begitu reaktivitas lebih meningkat dan mempengaruhi interaksinya dengan anak, hal ini membuat ibu menjadi lebih dapat mengatasi stres yang dialaminya. Dengan kemampuan tersebut, maka stres pengasuhan yang dialami oleh orangtua menjadi lebih minim.

Dalam hal ini, ketika seorang ibu tidak mampu mengatasi tuntutan yang dimilikinya sebagai orangtua, maka ibu dapat mengalami stres pengasuhan. Ketika ibu mengalami stres pengasuhan, maka perasaan senang dalam mengasuh anak berkurang, karena lebih banyak konflik maupun pengorbanan yang dilakukan. Oleh karena itu, agar dapat melakukan tugas pengasuhan dengan baik, ibu perlu untuk hadir sepenuhnya saat melakukan 
berbagai tugas pengasuhan anak seperti memiliki ekspektasi yang diiringi dengan penerimaan, mendampingi dan mengajari anak-anaknya terkait kemampuan maupun keterampilan yang dimiliki, salah satunya yaitu calistung. Hal-hal ini dapat dilakukan oleh ibu melalui sebuah keterampilan pengasuhan yang disebut dengan mindful parenting.

Dengan hadir sepenuhnya, ibu dapat lebih menikmati peran dan tugasnya sebagai orangtua sehingga baik ibu dan anak akan merasakan dampak positif dalam interaksi mereka. Hal ini dapat terjadi karena saat mengaplikasikan mindful parenting, ibu akan melakukan penerapan pengasuhan yang lebih konsisten dan berfokus pada tujuan, memiliki regulasi emosi yang lebih baik, maupun menjadi lebih pemaaf, lebih hangat dan responsif kepada anak mereka (Coatsworth \& Greenberg, 2009; Bazzano, Wolfe, Zylowska, Wang, Schuster, Barrett, \& Lehrer, 2015; Bogels, Hellemans, van Deursen, Romer, \& van der Meulen, 2013; Haydicky, Shecter, Wiener, \& Ducharme, dalam Han, Ahemaitijiang, Yan, Hu, Parent, Dale, DiMarzio, \& Singh, 2019).

Melalui mindful parenting, orangtua akan memiliki kesadaran penuh dalam proses pengasuhan sehingga biasanya orangtua memiliki kemampuan regulasi emosi dan kemampuan pemecahan masalah yang lebih baik melalui mendengarkan, meningkatkan kesadaranreaksiinternal, danmerespondengan lebih baik serta tenang ketika dihadapkan pada situasi emosional (Benn, Akiva, Arel, \& Roeser, dalam McCaffrey, Reitman, \& Black, 2016). Ibu yang mengaplikasikan mindful parenting lebih mungkin untuk mengembangkan ekspektasi yang diiringi dengan penerimaan terhadap anak. Hal ini akan membantu ibu menangani situasi tersebut dengan lebih baik dan berfokus pada tujuan pengasuhan yang telah ditetapkan. Banyaknya sumber daya yang dikeluarkan serta pengorbanan yang dilakukan dalam proses mengasuh anak akan lebih mungkin untuk dipandang dengan lebih positif karena ibu berfokus pada tujuan yang lebih besar.

Berdasarkan hasil uji hipotesis penelitian terkait besaran peran mindful parenting diperoleh hasil sebesar 39,7 persen. Peneliti berasumsi bahwa terdapat faktor lain yang mempengaruhi kondisi stres pengasuhan pada individu. Nomaguchi dan Brown (dalam Nomaguchi \& Johnson, 2016) berpendapat bahwa ibu dengan latar belakang pendidikan yang tinggi lebih mungkin untuk mengalami stres pengasuhan. Hal ini dapat disebabkan oleh pemikiran bahwa mereka merasa terjebak di dalam peran pengasuhan dan tekanan untuk lebih menginvestasikan waktu mereka dalam suatu karir. Selain itu, penelitian lain menemukan bahwa orangtua yang berusia lebih tua melaporkan stres pengasuhan yang lebih sedikit (Garrison, Blalock, Zarski, \& Merrit, 1997; Nomaguchi \& Brown, dalam Nomaguchi \& Johnson, 2016). Tidak hanya itu, penelitian Nomaguchi dan Brown (dalam Nomaguchi \& Johnson, 2016) juga menyebutkan bahwa jumlah anak yang dimiliki berkaitan dengan tingkat stres pengasuhan yang dialami oleh orangtua. Hal ini dapat dipengaruhi oleh kesejahteraan, masalah kesehatan atau perilaku yang dimiliki oleh anak. Walau demikian, di dalam penelitian ini, peneliti tidak melakukan uji beda data demografi responden berdasarkan tingkat pendidikan, usia, dan jumlah anak dikarenakan jumlah responden dalam penelitian ini tidak proporsional sehingga dikhawatirkan hasilnya tidak dapat merepresentasikan keadaan yang sebenarnya. Hal didasarkan pada salah satu syarat untuk melakukan uji beda independent sample $t$-test yaitu jumlah subjek di tiap kelompok yang dibandingkan sebaiknya sama atau jumlahnya tidak jauh berbeda (Widhiarso, 2011).

Karakteristik sampel dalam penelitian yang spesifik kepada ibu dengan anak usia sekolah dasar dapat menjadi suatu kelebihan karena penelitian sebelumnya yang lebih terfokus pada orangtua dengan anak bayi maupun remaja. Walau demikian, peneliti menyadari banyak kekurangan dan keterbatasan dari penelitian ini. Peneliti tidak mengukur faktor-faktor lain yang mempengaruhi stres pengasuhan seperti tingkat pendidikan, usia, dan jumlah anak. Penyebaran sampel dalam penelitian ini juga belum merata dalam berbagai variabel demografi seperti pengeluaran, tingkat pendidikan, jumlah anak, 
dan usia. Mayoritas sampel dalam penelitian ini memiliki tingkat pendidikan SMA $(72,7 \%)$, memiliki pengeluaran $\geq 8.700 .000 /$ bulan $(88,7 \%)$, pekerjaan sebagai ibu rumah tangga $(92,7 \%)$ dan mayoritas memiliki kurang atau sama dengan 2 orang anak $(81,8 \%)$, sehingga variasi data dalam penelitian ini menjadi berkurang. Secara umum, hasil penelitian yang terdapat dalam penelitian ini telah memberikan tambahan data serta wawasan baru mengenai mindful parenting khususnya pada ibu yang memiliki anak usia sekolah dasar, namun belum memberikan gambaran lengkap pada kelompok populasi lainnya sehingga perlu diteliti lebih lanjut dengan data yang lebih bervariasi.

\section{Kesimpulan}

Terdapat peran mindful parenting terhadap stres pengasuhan pada ibu yang memiliki anak usia sekolah dasar. Berdasarkan hasil penelitian yang telah dilakukan, mindful parenting memiliki peran terhadap stres pengasuhan yang lebih rendah dimana besaran perannya yaitu sebesar $39,7 \%$. Hal tersebut menunjukkan bahwa ketika ibu mengaplikasikan mindful parenting maka semakin rendah stres pengasuhan yang dialaminya.

Untuk penelitian selanjutnya, apabila ingin menggunakan ibu sebagai sampel penelitian dan melihat pengaruh eksternal terhadap stres pengasuhan seperti usia orangtua, status pendidikan, status pernikahan, dan lainnya dapat menggunakan quota sampling agar data yang didapatkan lebih mendalam. Hal ini dikarenakan dengan menggunakan quota sampling maka peneliti selanjutnya dapat memiliki target jumlah sampel yang diinginkan sehingga peneliti dapat memilih sampel secara bebas sesuai dengan karakteristik yang ditentukan berdasarkan pengaruh eksternal terhadap stres pengasuhan.

Penelitian ini tidak mengklasifikasi subjek ibu yang memiliki anak dengan kriteria bekerja ataupun ibu rumah tangga (tidak ada melihat kegiatan atau kesibukan yang ibu lakukan), sehingga subjek penelitian ini hanyalah ibu yang memiliki anak usia sekolah dasar. Berdasarkan hal tersebut, bagi penelitian selanjutnya yang ingin meneliti variabel yang sama, dapat melakukan penelitian perbandingan atau dengan populasi lainnya yaitu terfokus pada ibu yang bekerja dengan ibu rumah tangga. Dengan demikian, hasil yang diperoleh dapat lebih terfokus pada ibu yang bekerja atapun ibu rumah tangga serta data yang diperoleh dapat digeneralisasi pada populasinya.

\section{Daftar Pustaka}

Afiatin, T., Reginasari, A., Pratomo, A. W., Hamidah A. C., Wahyuni, N. S., Aiyuida, N., Fitriani, Y, dkk. (2018). Psikologi Perkawinan dan Keluarga: Penguatan Keluarga di Era Digital Berbasis Kearifan Lokal. Yogyakarta: Penerbit Kanisius.

Anastasi, A., \& Urbina, S. (2006). Tes Psikologi. PT Indeks: Jakarta

Anggraini, C. (2018). "Hubungan antara Mindful Parenting dengan Stres Pengasuhan pada Ibu yang Memiliki Anak Usia 3-6 Tahun serta Tinjauannya dalam Islam". Skripsi. Fakultas Psikologi. Universitas YARSI: Jakarta.

Azwar, S. (2016). Reliabilitas dan Validitas. Pustaka Pelajar: Yogyakarta.

Baqutayan, S. M. S. (2015). Stress and coping mechanism: a historical overview. Mediterranean Journal of Social Sciences, 6(2), 479- 488.

Beer, M., Ward, L., Moar, K. (2013). The relationship between mindful parenting and distress in parents of children with an autism spectrum disorder. Mindfulness, 4 , 102-112.

Berry, J. O., \& Jones, W. H. (1995). The parental stress scale: initial psychometric evidence. Journal of Social and Personal Relationships, 12(3), 463-472.

Bögels, S. M., Hellemans, J., van Deursen,S., Römer,M., \& van der Meulen, R. (2013). Mindful parenting in mental health care: effects on parental and childpsychopathology, parental stress, parenting, coparenting, and marital functioning. Mindfulness, 5, 536-551. doi: 10.1007/s12671-013-0209-7 
Bögels, S., Lehtonen A., \& Restifo, K. (2010). Mindful parenting in mental health care. Mindfulness, 1, 107-120.

Bornstein, M. H. (2013). Parenting and child mental health: a cross-cultural perspective. World Psychiatry, 12, 258-265.

Bornstein, M. (2002). Handbook of Parenting Volume 1: Children and Parenting. New Jersey: Lawrence Erlbaum Associates, Publishers.

Bornstein, M. (2002). Handbook of Parenting Volume 3: Being and Becoming a Parent. New Jersey: Lawrence Erlbaum Associates, Publishers.

Chung, K.M., Ebesutani, C., Bang, H. M., Kim, J., Chorpita, B. F., Weisz, J. R., Suh, D., \& Byun, H. (2013). Parenting stress and child behavior problems among clinicreferred youth: cross-cultural differences across the us and korea. Child Psychiatry Human Development, 44, 460-468.

Corthorn, C., \& Milicic, N. (2016). Mindfulness and parenting: a correlational study of non meditating mothers of preschool children. Journal of Child and Family Studies, 25,1672-1683. doi: 10.1007/s10826-015$0319 z$.

Cronin, S., Becher, E. H., Christians, K. S., Maher, M., \& Dibb, S. (2015). Parents and Stress: Understanding Experiences, Context, and Responses. Children Mental Health eReview. Minnesota: University of Minessota.

Deater-Deckard, K. (2004). Parenting Stress. London: Yale University Press.

Del Giudice, M. (2014). Middle childhood: an evolutionary - developmental synthesis. Child Development Perspectives, O(0), 1-8.

Duncan, L. G., Coatsworth, J. D., Greenberg, M. T. (2009). a model of mindful parenting: implications for parent-child relationships and prevention research. Clinical Child Family Psychological Rev, 12, 255-270.

Feizi A, Najmi B, Salesi A, Chorami M, Hoveidafar R. (2014). Parenting stress among mothers of children with different physical, mental, and psychological problems. J Res Med Sci, 19(2):145152.
Gehart, D. R. (2012). Mindfulness and Acceptance in Couple and Family Therapy. New York: Springer.

Geurtzen, N., Scholte, R. H., Engels, R. C. M. E., Tak, Y. R., \& van Zundert, R. M. P. (2014). Association between mindful parenting and adolescents' internalizing problems: non- judgemental acceptance of parenting as core element. Journal of Child and Family Studies, 24, 1117-1128. doi: 10.1007/s10826-014-9920-9.

Gouveia, M. J., Carona, C., Canavarro, M. C., \& Moreira, H. (2016). self compassion and dispositional mindfulness are associated with parenting styles and parenting stress: the mediating role of mindful parenting. Mindfulness, 7, 700-712.

Han, Z. R., Ahemaitijiang, N., Yan, J., Hu, X., Parent, J., Dale, C., DiMarzio, K., dkk. (2019). Parent mindfulness, parenting, and child psychopathology in china. Mindfulness.https://doi.org/10.1007/ s12671-019-01111-z

Katkic, L. O., Morovic, M. L., \& Kovacic, E. (2017). Parenting stress and a sense of compliance in mothers of children with and without developmental disabilities. Hrvatska revija za rehabilitacijska istraživanja, 53, 63-76.

Kumar, R. (1999). Research Methodology. Malaysia: Sage Publication.

Lestari, S. (2012). Psikologi Keluarga : Penanaman Nilai \& Penanganan Konflik dalam Keluarga. Jakarta: Kencana Prenamedia Group.

Lestari, S., \& Widyawati, Y. (2016). Gambaran parenting stress dan coping stress pada ibu yang memiliki anak kembar. Jurnal Psikogenesis, 4(1), 41-57.

Lima, M. B. S., Cardoso, V. D. S., \& da Costa Silva, S. S. (2016). Parental stress and social support of caregivers of children with cerebral palsy. Paidéia, 26(64), 207214. doi:10.1590/1982-43272664201608

McCaffrey, S., Reitman, D., \& Black, R. (2016). Mindfulness in parenting questionnaire (mipq): development and validation of a measure of mindful parenting. Mindfulness, 8: 232.doi:https://doi.org/10.1007/s12671016-0596-7 
Medeiros, C., Gouveia, M. J., Canavarro, M. C. \& Moreira, H. (2016). The indirect effect mindful parenting of mothers and fathers on the child's perceived wellbeing through the child's attachment to parents. Mindfulness, 7(4), 916-927. doi:10.1007/s12671-0160530-z

Meppelink, R., de Bruin, E. I., WandersMulder, F. H., Vennick, C. J., \& Bögels,S. M. (2016). Mindful parenting training in child psychiatric settings: heightened parental mindfulness reduces parents' and children's psychopathology. Mindfulness, 7(3), 680-689. doi:10:1007/s12671-0160504-1.

Molchanov, S. V. (2013). The moral development in childhood. Social and Behavioral Sciences, 86, 615-620.

Mulsow, M., Caldera, Y. M., Pursley, M., Reifman, A., \& Huston, A. C. (2002). Multilevel factors influencing maternal stress during the first three years. Journal of Marriage and Family, 64(4), 944-956. doi:10.1111/j.1741-3737. 2002.00944.x

Nisfiannoor, M. (2009). Pendekatan Statistika Modern. Jakarta: Salemba Humanika.

Nomaguchi, K. M., \& Brown, S. L. (2011). Parental strains and rewards among mothers: the role of education. Journal of Marriage and Family, $\quad$ 73(3), 621-636.

Nomaguchi, K., \& House, A. (2013). Racialethnic disparities in maternal parenting stress: the role of structural disadvantages and parenting values. Journal of Health and Social Behavior, 54(3), 386-404. doi: $10.1177 / 0022146513498511$

Nomaguchi, K., \& Johnson, W. (2016). Parenting stress among low-income and working-class fathers: the role of employment. Journal of Family Issues. 37(11), 1535- 1557.

Papalia, D. E., Olds, S. W., \& Feldman, R D. (2004). Human Development. New York: McGraw-Hill.

Pepping, A. C., O'Donovan, A., \& Davis, P. J. (2014). The differential relationship between mindfulness and attachment in experienced and inexperiencedmeditator. Mindfulness, 5,392-399.doi:10.1007/s12671-012-01933
Pickard, J. A., Townsend, M., Caputi, P., \& Grenyer, B. F. S. (2017). Observing the influence of mindfulness and attachment styles through mother and infant interaction: a longitudinal study. Infant Mental Health Journal, 00(0), 1-7. doi: 10.1002/imhj.21645

Pinquart, M. (2017). Parenting stress in caregivers of children with chronic physical condition- a meta analysis. Stress and Health, 1-11.

Santrock, J. W. (2013). Life Span Development. $14^{\text {th }}$ Ed. New York: McGraw-Hill

Seniati, L., Yulianto, A., \& Setiadi, B. N. (2015). Psikologi Eksperimen. Jakarta: PT. Indeks.

Skreden, M., Skari, H., Malt, U. F., Pripp, A. H., Björk, M. D., Faugli, A., \&

Emblem, R. (2012). Parenting stress and emotional wellbeing in mothers and fathers of preschool children. Scandinavian Journal of Public Health, 40(7), 596-604. doi:10.1177/1403494812460347

Sugiyono. (2012). Statistika untuk Penelitian. Bandung: Alfabeta.

Sugiyono. (2014). Statistika untuk Penelitian. Bandung: Penerbit Alfabeta.

Tavakol, M. \& Dennick, R. (2011). Making sense of cronbach's alpha. International Journal of Medical Education, 2, 53-55.

Venkatesh, K. K., Phipps, M. G., Triche, E. W., \& Zlotnick, C. (2014). The relationship between parental stress and postpartum depression among adolescent mothers enrolled in a randomized controlled prevention trial. Maternity of Children Health Journal, 18,1532-1539.doi:10.1007/ s10995-013-1394-7

Webster-Stratton, C. (1990). Stress: a potential disruptor of parent perceptions and family interactions. Journal of Clinical Child Psychology, 19(4), 302-312.

Widarsson, M., Engström, G., Rosenblad, A., Kerstis, B., Edlund, B., \& Lundberg, P. (2013). Parental stress in early parenthood among mothers and fathers in sweden. Scandinavian Journal of Caring Sciences, 27, 839-847. doi: 10.1111/j.14716712.2012.01088.x

Widhiarso, W. (2010). Uji Linearitas Hubungan. Manuskrip. Tidak diterbitkan. Fakultas 
Psikologi. Universitas Gadjah Mada: Yogyakarta.

Zelman, J. J., \& Ferro, M. A. (2018). The parental stress scale: psychometric properties in families of children with chronic health conditions. Interdisciplinary Journal of Applied Family Studies, 1-13.

The 2017 Global Least and Most Stressful Cities Ranking. Diperoleh di https://www. zipjet.co.uk/2017-stressful-cities-ranking pada 19 Maret 2018.

Widhiarso, W. (2011). Uji Hipotesis Komparatif. Diperoleh dari http://widhiarso.staff.ugm. ac.id/files/membaca t-tes.pdf pada $25 \mathrm{Mei}$ 2019.

Marbun, J. (2015). Pentingnya Peran OrangTua dalam Belajar Anak. Diperoleh dari https:// www.republika.co.id/berita/pendidikan/ eduaction/15/01/08/nhtpql-pentingnyaperan-orang-tua-dalam-belajar-anak pada 23 Mei 2019.

Hasibuan, I. G. (2015). OrangTua Siswa Keluhkan Penerapan Program Pendidikan 2013. Diperoleh dari https:// suaraindonesia-news.com/orang-tuasiswa-keluhkan-penerapan-programpendidikan-2013/ pada 23 Mei 2019. 